\title{
PERSONALITY TRAITS AND PERCEIVED USABILITY EVALUATION OF E-LEARNING PLATFORMS: A CASE STUDY
}

\author{
Prokopia Vlachogianni ${ }^{1}$, Nikolaos Tselios ${ }^{1}$ and Michalis Xenos ${ }^{2}$ \\ ${ }^{I}$ Department of Educational Sciences and Early Childhood Education, University of Patras \\ ${ }^{2}$ Computer Engineering and Informatics Department, University of Patras \\ 26500 Patras, Rio, Greece
}

\begin{abstract}
The impact of individuals' characteristics on the perceived usability of e-learning systems is a significant, but rather overlooked topic. The goal of this research is to investigate the relation between teachers' personality traits and their perceived usability of the e-class platform using the System Usability Scale (SUS) and the Big 5 Personality test. 1324 teachers of primary and secondary education in Greece participated in the study. Results indicated satisfactory usability levels for the e-class $(\mathrm{M}=69.68, \mathrm{SD}=15.24)$. Moreover, $\mathrm{SUS}$ scores found to be correlated with teachers' ICT in education competency and educational stage. Furthermore, secondary school teachers and teachers holding a PhD or a master's degree rated significantly higher than the primary school teachers and teachers holding only BSc or high school diploma, respectively. However, SUS score was not correlated with age, gender, work experience, private/public school, work relationship (tenured or not) and general ICT competency. Finally, all five personality traits (Extraversion, Conscientiousness, Openness to new experience, Emotional stability, Agreeableness) found to be significantly positive correlated with perceived usability of the e-class platform.
\end{abstract}

\section{KEYWORDS}

Usability, Personality, User Experience, System Usability Scale (SUS), Big 5, E-Class, E-Learning, Learning Management Systems (LMS), Primary Education, Secondary Education, Teachers

\section{INTRODUCTION}

E-learning platforms are widely used in all educational stages. The successful adoption and use of a platform depends to a large extent on the satisfactory interaction with the user and consequently on its perceived usability (Ardito et al., 2006; Altanopoulou \& Tselios, 2017; Tselios et al., 2008). However, even on the same platform the usability ratings may differ depending on the user. It is argued that participants' inherent personality characteristics as well as demographics influence their perceived usability ratings. Thus, the main goal of this study is to examine whether the teachers' personality traits are related with their perceived usability ratings of a widely adopted e-learning platform.

Perceived usability was evaluated by using System Usability Scale (Brooke, 1996) which is the most widely adopted questionnaire for perceived usability evaluation of software and products (Tullis \& Albert, 2008). Personality traits were measured with the Big 5 Personality test developed by Goldberg (1992). The Big 5 model gives emphasis on five major personality dimensions: Extraversion, Conscientiousness, Openness to new experience, Emotional stability, and Agreeableness.

Previous research findings concerning the influence of personality to the perceived usability are quite inadequate. Kortum and Oswald (2018) in a dataset of 268 participants rated the perceived usability of 20 everyday products considering the personality traits. Openness to new experience and Agreeableness had the strongest positive correlations with SUS score. Furthermore, in a usability testing of a website conducted by Burnett \& Ditsikas (2006) five participants with high scores at extraversion found $40 \%$ more usability problems comparing five participants with high scores at introversion. Using a sample of 603 participants, Oliveira et al. (2013) found that Extraversion and Conscientiousness had significant positive correlation with perceived usability of mobile services. 
The study presented in this paper has been guided by the following research questions:

RQ1: What are the usability levels of the e-class platform used in primary and secondary education?

RQ2: Which factors seem to be related with SUS score (e.g. age, gender, stage of education, highest level of education, work experience, private/public school, work relationship, school district, and ICT competency)?

RQ3: Is there any relationship between the personality traits and the perceived usability evaluation of the e-class platform used in primary and secondary education in Greece?

\section{METHODOLOGY}

The participants were 1324 teachers of primary and secondary education in Greece who used e-class platform for distance learning purposes. E-class platform is a Learning Management System provided by the Ministry of Education in Greece. $72.7 \%$ of the participants were female, aged 24-67 with a mean age of 45.92 (SD=9.66) years. A questionnaire has been used which comprised a demographics section, and the Greek versions of the System Usability Scale (Brooke, 1996) and the Big Five personality test (Goldberg, 1992) The online questionnaire was distributed through e-mail and social networks from May 18, 2020 to June 20, 2020. SPSS v25 was used for the data analysis.

\section{RESULTS}

\section{RQ1: Perceived usability levels of the e-class platform}

Mean SUS score of e-class platform is 69.68 ( $\mathrm{SD}=15.24)$. In specific, for primary education participants $(\mathrm{N}=545)$ mean SUS rating is $68.18(\mathrm{SD}=15.45)$ and for secondary education participants $(\mathrm{N}=779)$ mean SUS rating is $70.73(\mathrm{SD}=15)$. Considering the criteria set from Bangor et al. (2009) the e-class platform seems to have satisfactory usability levels but with some issues.

\section{RQ2: Factors related with SUS score}

Normal distribution is violated for SUS scores as it is demonstrated by using Kolmogorov-Smirnov and Shapiro-Wilk tests. Possible correlations between the age of participants, gender, stage of education, highest level of education, work experience, private/public school, work relationship, school district, ICT competency and the mean SUS score for the e-class platform were investigated.

No significant correlation was found between SUS score and a) age ( $\mathrm{rs}=-0.017, \mathrm{p}=0.545$, ns), b) gender ( $\mathrm{U}=169088, \mathrm{Z}=-0.765, \mathrm{p}=0.444, \mathrm{~ns}), \mathrm{c})$ work experience ( $\mathrm{rs}=-0.013, \mathrm{p}=0.635, \mathrm{~ns}), \mathrm{d})$ private/public school ( $\mathrm{U}=4894, \mathrm{Z}=-0.344, \mathrm{p}=0.731$, ns), e) work relationship ( $\mathrm{p}=0.411$, ns) and $\mathrm{f}$ ) basic level ICT competency $(\mathrm{U}=109712, \mathrm{Z}=-1.601, \mathrm{p}=0.109, \mathrm{~ns})$. Mann-Whitney $\mathrm{U}$ test examined the relationship between SUS score and educational stage. Teachers' ratings at secondary schools are statistically significantly higher than those of primary education $(\mathrm{U}=190537, \mathrm{Z}=-3.179, \mathrm{p}=0.001, \mathrm{~s})$. In addition, teachers' SUS ratings holding a master's and/or a $\mathrm{PhD}$ degree were statistically significantly higher than those holding a bachelor's $(\mathrm{p}<.001, \mathrm{~s}, \mathrm{p}=0.012$, $\mathrm{s})$ a degree of technological educational institution $(\mathrm{p}=0.029, \mathrm{~s}, \mathrm{p}=0.023, \mathrm{~s})$ or a high school diploma $(\mathrm{p}=0.021$, $\mathrm{s}, \mathrm{p}=0.013, \mathrm{~s})$, respectively. A significant correlation was also found between SUS score and ICT competency specialized in educational purposes $(\mathrm{U}=1080063, \mathrm{Z}=-5.621, \mathrm{p}<.001, \mathrm{~s})$. Teachers serving in urban districts gave statistically significantly higher SUS ratings than those located in semi-urban areas $(\mathrm{p}=0.018, \mathrm{~s})$ and teachers in rural districts gave higher SUS ratings than those at semi-urban areas as well $(\mathrm{p}=0.045, \mathrm{~s})$.

\section{RQ3: Personality traits and perceived usability}

Possible relationship was examined between perceived usability and the personality traits, as they were derived from the SUS scores at System Usability Scale and Big 5 personality test, respectively (see Table 1). All five major personality traits were significantly correlated with SUS score; Extraversion ( $r s=0.094, p=0.001$, $\mathrm{s})$, Agreeableness ( $\mathrm{rs}=0.125, \mathrm{p}<.001, \mathrm{~s})$, Conscientiousness ( $\mathrm{rs}=0.202, \mathrm{p}<.001, \mathrm{~s})$, Emotional Stability $(\mathrm{rs}=0.174, \mathrm{p}<.001, \mathrm{~s})$, Openness to new experience $(\mathrm{rs}=0.166, \mathrm{p}<.001, \mathrm{~s})$ and Total Big 5 score $(\mathrm{rs}=0.247$, $\mathrm{p}<.001, \mathrm{~s})$. 
Table 1. Participants' personality traits and correlation with their SUS ratings

(* and ** indicate significance at the $\mathrm{p}=0.05$ and 0.01 level respectively)

\begin{tabular}{|l|c|c|c|}
\hline & Mean & SD & SUS-trait correlation (r) \\
\hline Extraversion & 32.21 & 6.59 & $0.094^{* *}$ \\
\hline Agreeableness & 42.33 & 5.14 & $0.125^{* *}$ \\
\hline Conscientiousness & 40.23 & 6.1 & $0.202^{* *}$ \\
\hline Emotional Stability & 31.17 & 7.54 & $0.174^{* *}$ \\
\hline Openness to new experience & 37.88 & 5.70 & $0.166^{* *}$ \\
\hline Total Big 5 score & 183.82 & 19.01 & $0.247^{* *}$ \\
\hline
\end{tabular}

\section{CONCLUSIONS AND DISCUSSION}

This paper sheds light in a significant research issue concerning the impact of personality traits on the perceived usability of the e-class platform. Individual-related factors which affect the perceived usability of a platform are often overlooked. Usability benchmarks are provided for the e-class platform and possible correlations between SUS score and a) gender, b) age, c) stage of education, d) teachers' highest level of education, e) work experience, f) private/public school, g) work relationship (tenured or not), h) school district and i) ICT competency were examined. The findings of this paper can be used as a useful benchmarking guide for improving the usability of e-class platform.

Regarding the research questions, e-class $(M=69.68, S D=15.24)$ seems to have good usability levels but not without flaws, according to the criteria set by Bangor et al. (2009). This result comes in line with Vlachogianni et al. (2020) who analyzed usability benchmarks for 40 Learning Managements Systems and found their mean SUS score $66.88(\mathrm{SD}=10.88)$. Furthermore, no significant correlation was found between SUS score and age $(\mathrm{rs}=-0.017, \mathrm{p}=0.545, \mathrm{~ns})$. Previous research results are quite contradictory regarding the relation of these two variables (Binyamin et al., 2016; Orfanou et al. 2015; Granić and Ćukušić, 2011; Bangor et al., 2008; Mujinga et al., 2018). No correlation was also found between gender and SUS score that is validated by previous research findings (Harrati et al., 2016; Kortum, \& Sorber, 2015; Bangor et al., 2008; Ituma 2011; Orfanou et al., 2015; Ng et al., 2011; Berkman \& Karahoca, 2016; Tossell et al., 2012).

Teachers of secondary education found e-class significantly more usable than those of primary education. This may be related to the general experience they gain interacting with their students using the platform. Students at secondary education usually have more advanced ICT skills compared to primary school children. Therefore, they might experience fewer issues when interacting with the platform. Teachers holding a PhD or a master's degree have statistically significant higher rates at SUS score than the rest. This could be explained by an underlying persistency which high achievers might possess. Thus, such persistency might have been expressed in the context of the study as an intrinsic motivation to learn how to effectively interact with the platform. Teachers at semi-urban school districts gave lower SUS scores in comparison to those at urban $(\mathrm{p}=0.018, \mathrm{~s})$ and rural $(\mathrm{p}=0.045, \mathrm{~s})$ districts, respectively. Moreover, teachers with ICT competency specialized in educational purposes rated statistically significantly higher at SUS.

Furthermore, all five personality traits found to be correlated with the perceived usability of e-class platform. That result is partially in line with the results reported by Kortum and Oswald (2018) who found Agreeableness and Openness to new experience have a significant correlation with SUS score.

The current study is not without limitations. First, teachers with lower internet competency skills may have been excluded since the questionnaire was distributed online. Second, generalization of the results obtained is questionable since they concern a partial and perhaps not representative sample of teachers in Greece. Thus, further research analysis using complementary approaches to refine the sampling procedure used might have a significant contribution in terms of validation of the current results.

As far as future work is concerned, it would be interesting to further investigate the impact personality traits have on the perceived usability of the e-class platform. In addition, the expected learning gain should be examined in relation to the perceived usability and the personality traits. Finally, the presented study can be expanded to consider more e-learning platforms used in primary and secondary education to reach more robust conclusions related to the influence of personality on the perceived usability evaluation. 


\section{ACKNOWLEDGEMENT}

Part of the work presented in this paper has been completed in the context of the project: "ERMIS-F: Web services for environmental risk-Floods". Funding: Interreg V-A Greece - Cyprus.

\section{REFERENCES}

Altanopoulou, P., \& Tselios, N. (2017). Assessing acceptance toward wiki technology in the context of Higher Education. The International Review of Research in Open and Distributed Learning (IRRODL), 18(6), 127-149.

Ardito, C., Costabile, M. F., De Marsico, M., Lanzilotti, R., Levialdi, S., Roselli, T., \& Rossano, V. (2006). An approach to usability evaluation of e-learning applications. Universal access in the information society, 4(3), 270-283.

Bangor, A., Kortum, P. T., \& Miller, J. T. (2008). An empirical evaluation of the system usability scale. Intl. Journal of Human-Computer Interaction, 24(6), 574-594.

Bangor, A., Kortum, P., \& Miller, J. (2009). Determining what individual SUS scores mean: Adding an adjective rating scale. Journal of usability studies, 4(3), 114-123.

Berkman, M. I., \& Karahoca, D. (2016). Re-assessing the usability metric for user experience (UMUX) scale. Journal of Usability Studies, 11(3), 89-109.

Binyamin, S., Rutter, M., \& Smith, S. (2016, November). The utilization of system usability scale in learning management systems: A case study of Jeddah Community College. In the 9th International Conference of Education, Research and Innovation (ICERI2016), International Academy of Technology, Education and Development, Seville, Spain.

Brooke, J. (1996). SUS-A quick and dirty usability scale. Usability evaluation in industry, 189(194), 4-7.

Burnett, G. E., \& Ditsikas, D. (2006, December). Personality as a criterion for selecting usability testing participants. In Proceedings of the International Conference on Information and Communications Technologies, 599-604.

Goldberg, L. R. (1992). The development of markers for the Big-Five factor structure. Psychological assessment, 4(1), 26-42.

Granić, A., \& Ćukušić, M. (2011). Usability testing and expert inspections complemented by educational evaluation: A case study of an e-learning platform. Journal of Educational Technology \& Society, 14(2), 107-123.

Harrati, N., Bouchrika, I., Tari, A., \& Ladjailia, A. (2016). Exploring user satisfaction for e-learning systems via usage-based metrics and system usability scale analysis. Computers in Human Behavior, 61, 463-471.

Ituma, A. (2011). An evaluation of students' perceptions and engagement with e-learning components in a campus-based university. Active Learning in Higher Education, 12(1), 57-68.

Kortum, P., \& Oswald, F. L. (2018). The impact of personality on the subjective assessment of usability. International Journal of Human-Computer Interaction, 34(2), 177-186.

Kortum, P., \& Sorber, M. (2015). Measuring the usability of mobile applications for phones and tablets. International Journal of Human-Computer Interaction, 31(8), 518-529.

Mujinga, M., Eloff, M. M., \& Kroeze, J. H. (2018). System usability scale evaluation of online banking services: A South African study. South African Journal of Science, 114(3-4), 1-8.

Ng, A. W., Lo, H. W., \& Chan, A. H. (2011). Measuring the Usability of Safety Signs: A use of system usability scale (SUS). In proceedings of the International MultiConference of Engineers and Computer Scientists, 16-18 March 2011, Hong Kong, China.

Oliveira, R. D., Cherubini, M., \& Oliver, N. (2013). Influence of personality on satisfaction with mobile phone services. ACM Transactions on Computer-Human Interaction (TOCHI), 20(2), 1-23.

Orfanou, K., Tselios, N., \& Katsanos, C. (2015). Perceived usability evaluation of learning management systems: Empirical evaluation of the System Usability Scale. International Review of Research in Open and Distributed Learning, 16(2), 227-246.

Tossell, C. C., Kortum, P., Shepard, C., Rahmati, A., \& Zhong, L. (2012). An empirical analysis of smartphone personalisation: measurement and user variability. Behaviour \& Information Technology, 31(10), 995-1010.

Tselios, N., Avouris, N., \& Komis, V. (2008). The effective combination of hybrid usability methods in evaluating educational applications of ICT: Issues and challenges. Education and Information Technologies, 13(1), 55-76.

Tullis, T., \& Albert, B. (2008). Measuring the user experience: Collecting. Analyzing, and Presenting Usability Metrics. Elsevier.

Vlachogianni, P., Tselios, N., \& Xenos, M. (2020). Perceived usability of Learning Management Systems and University Websites: A systematic review. In Proceedings of the 14th International Conference on Interfaces and Human Computer Interaction, 23 - 25 July 2020, Zagreb, Croatia. 